DULCE MA. GRANJA

\title{
En memoria de Michel Foucault
}

EL 25 DE junio de este año murió en París Michel Foucault. Dedicamos un pequeño espacio de nuestros "estudios" para recordar la vida, el pensamiento y la obra de uno de los filósofos que más ha influenciado en nuestro convulsionado siglo XX.

El pensamiento de Foucault se caracteriza por un amplio proyecto: crear un espacio propio para la arqueología de las ciencias humanas. Ellas deben "despertar de su sueño dogmático"y comprender que el hombre es una invención reciente, no el tema más antiguo de la reflexión. Sus sarcasmos al humanismo y su cuestionamiento de la reflexión histórica han suscitado acaloradas discusiones. Sartre vio en él el designio de una nueva ideología antimarxista. Para otros, su peculiar perspectiva epistemológica es aberrante. Piaget dijo de ella: "es un estructuralismo sin estructuras". Se ha dicho de su libro Las palabras y las cosas que responde a una estrategia de mistificación. Pero otros ven en él el terreno preparatorio para una nueva "crítica de la razón pura". Se ha dicho de Foucault que es el "más brillante filósofo del poder". Pero también se ha dicho que "no ha hecho una sola investigación que no termine en el instinto". Un célebre antropólogo del Instituto de estudios a vanzados de la universidad de Princeton, Clifford Geertz, considera que sus objetos son imposibles: "un humanismo científico antihumanista, un historiador antihistórico".

El objeto de toda esta controversia fue un hombre siempre muy bien ataviado, que nació en la provincia de Poitiers en 1926. Foucault fue, desde 1970, profesor del célebre College de France, donde pudo crear por sí solo un nuevo campo del saber que designó con el nombre de "historia de los sistemas del pensamiento". La mayor parte de su trabajo intelectual fue hecha en su caro, pero austero, apartamento de París: las paredes pintadas de blanco y casi llenas de libros, la hermosa vista desde un octavo piso de las azoteas del viejo 
París; sólo un detalle de frivolidad en esta "torre de marfil": la planta de mariguana que crece entre las petunias que adornan la terraza. En este ambiente, Michel Foucault produjo una serie de libros penetrantes y en extremo influenciantes sobre los sutiles problemas de la libertad individual y la coerción social; analizó las relaciones entre la verdad y el poder, la enfermedad y la civilización, entre muchos otros temas. Foucault estaba por publicar el segundo de los cinco volúmenes de la Historia de la sexualidad. "No quise escribir un libro"-dijo Foucault - "sobre la conducta sexual. Lo que yo quería saber era. cuáles son las preguntas que la gente se formula sobre la sexualidad y por qué lo hace. ¿Por qué, por ejemplo, las preguntas sobre el sexo han desempeñado un importante papel en la práctica cristiana de la confesión durante los siglos XVI y XVII?"

Foucault fue hijo de un médico de la provincia de Poitiers. No obstante que no era de su agrado, estudió seriamente la psicología y llegó a tener una especial aversión por ella durante su trabajo como médico interno en el hospital de enfermedades mentales de Santa Ana en París. "Me sentía muy cercano y no muy distinto de los enfermos", afirmaba Foucault refiriéndose a aquél entonces. "Estaba yo intranquilo respecto a la profesión médica. Quedaba planteada frente a mí una pregunta que me inquietaba: ¿cuál es el poder de la medicina, cuál es su autoridad?"

Después de enseñar psicopatología en París y en la universidad sueca de Uppsala, el inquieto joven Foucault obtuvo plazas en Varsovia y Hamburgo. A pesar de la divagación y extravío tanto interno como externo, apareció Enfermedad y civilización, en donde Foucault inicia haciendo una poética y melancólica evocación de esos barcos medievales que en realidad eran las prisiones en las que se transportaban a los dementes lejos de sus comunidades.

Foucault se encontró con una pregunta histórica muy concreta a la que quiso dar respuesta: ¿por qué, durante 1656, varios hoteles y asilos de París fueron transformados en el hospital general de París? ¿Por qué instituciones similares se construyeron rápidamente en todas las ciudades de provincia? ¿Y por qué fueron llenadas no sólo con enfermos crónicos, sino también con dementes y desempleados? Foucault aventuró una respuesta: la aurora de la "edad de la razón" trajo también el despertar de una nueva clasificación, caracterización $\mathrm{y}$ diferenciación de normalidad y anormalidad, de salud y enfermedad, y por consiguiente, nuevas y radicales formas de regulación social de ellas. En lugar de considerar a los dementes como poseedores de un tipo especial de conocimiento - como se hacía en la edad media - se les menospreció y silenció. Foucault insistió en los cambios que comportan las definiciones de salud y enfermedad, las 
cuales, consideró el filósofo francés, son arbitrarias. En la medida en que intervienen en la definición de razón, ésta será también una definición cambiante y en esa misma medida arbitraria.

Muchos historiadores modernos sostienen que la historia fluye irremediablemente en una misma dirección determinada y que sus funciones son el trazar ese transcurrir con y para la libertad. Foucault pensó, por el contrario, que hay discontinuidad y separación entre un periodo histórico y otro. Cada edad nueva crea inconscientemente una nueva estructura o sistema intelectual para considerar al mundo. Foucault llamó a este sistema de pensamiento una episteme. Una de estas discontinuidades marcó, a mediados del siglo XVII, el inicio de la edad de la razón. Poco después se da otra separación: la revolución francesa que introduce la creencia en el progreso y en la evolución social y científica. Según Foucault, una tercera ruptura debe ocurrir ahora, pero no ofreció, hasta el día de su muerte, una definición clara y una explicación de cómo y por qué tal discontinuidad ha de presentarse.

Fue la rebelión estudiantil de 1968 en París lo que empujó a Foucault a encauzar su pensamiento en la dirección política. Pensó Foucault que el conocimiento es poder, es más: entre poder y conocimiento hay una implicación directa y recíproca de uno a otro. Si cada época histórica desarrolla nuevas formas y estructuras del conocimiento, nuevas formas de definir la vida y de concebir y ejercer el poder serán, consecuentemente, producidas. El poder militar es la forma más obvia de éste. Sin embargo - asume Foucault - todo conocimiento social, toda forma de investigación, cada categorización y cada juicio es también un ejercicio del poder. Evidentemente los profesores, doctores, sacerdotes, etc., toman parte en este ejercicio del poder; pero lo más importante es que el ciudadano moderno es adiestrado para ejercer este estado de poder en él mismo y en sus conciudadanos. Foucault escribe en Vigilar y castigar: "el verdadero político nos ata con cadenas más fuertes que las cadenas de hierro, pues nos ata con las cadenas de sus propias ideas y ese encadenamiento es tanto más fuerte en cuanto no sabemos de qué está hecho". Esta prisión intelectual es el hombre mismo, pues para Foucault no hay una naturaleza humana en espera de su liberación.

Michael Foucault, después de la segunda guerra mundial, se vio atraído por el marxismo: "me interesó pero me dejó insatisfecho [...] Marx en realidad fue un producto de la episteme del siglo XIX. Por esto la gente joven de mi generación se vio atraída por el marxismo pues encontró en él el medio para prolongar sus sueños adolescentes de un mundo mejor". Políticamente considerado, Foucault resultó inclasificable. Así declaró: "he vivido en Suecia, país de libertad, y en 
Polonia, país bastante opuesto; y estas experiencias me han mostrado que cualquiera que sea el sistema legal, el mecanismo del poder constriñe al individuo y dirige su conducta en un esfuerzo por normalizarlo".

Puede resultar exasperante el constante volver de Foucault sobre un problema y plantear nuevas preguntas que casi siempre quedan sin respuesta. No obstante, es cierto que Michel Foucault ejerció y sigue ejerciendo una extraña fascinación y despertando un creciente culto entre los estudiantes, tal vez porque es esta una época en la que, especialmente los jóvenes, se ven atrapados en los cientos de invisibles redes del control social. 